\title{
Extraction of a rectal foreign body using a custom-made giant snare
}

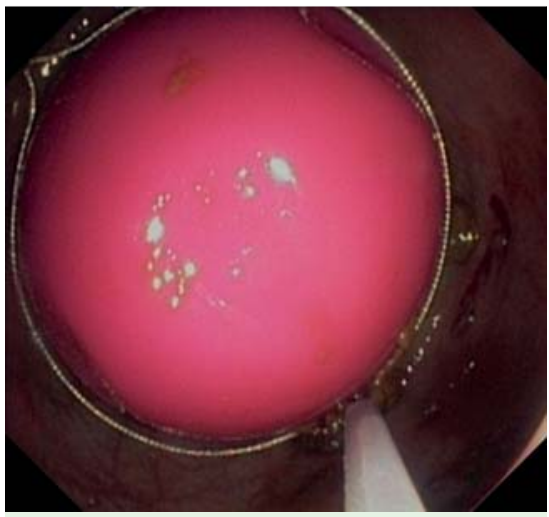

Fig. 1 The standard polypectomy snare was too small to grasp the foreign body.

Extraction of foreign bodies from the rectum is a major challenge in therapeutic endoscopy $[1,2]$. The use of a standard polypectomy snare is hampered in cases where the foreign body is slippery or too large to place the polypectomy snare around the foreign body.

A 33-year-old man presented to our emergency department several hours after inserting a vibrator into his rectum. At clinical examination there were no signs of perforation. At flexible sigmoidoscopy the vibrator was visualized in the distal sigmoid. Multiple attempts to grasp the distal part of vibrator with a standard $30-\mathrm{mm}$ polypectomy snare (Captivator, Boston Scientific, Natick, Massachusetts, USA) failed and the snare was deemed too small ( $\bullet$ Fig. 1 ). Grasping the proximal end of the vibrator failed for similar reasons. Moreover, attempts to facilitate the positioning of the snare around the vibrator with a forceps using a second endoscope were unsuccessful. Therefore, we decided to construct a giant snare using a folded $450-\mathrm{cm}$ guide wire (Jagwire, Boston Scientific, Natick, Massachusetts, USA) and a pusher from a 7-Fr endoscopic retrograde cholangiopancreatography (ERCP) biliary stent system (Flexima Biliary Stent System, Boston Scientific, Natick, Massachusetts, USA) ( Fig. 2 ).

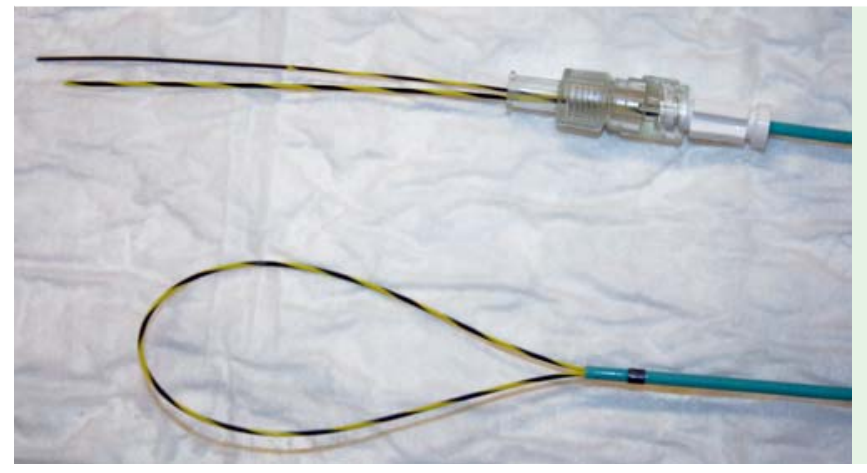

Fig. 2 Custom-made giant snare (using a guide wire and biliary stent pusher).

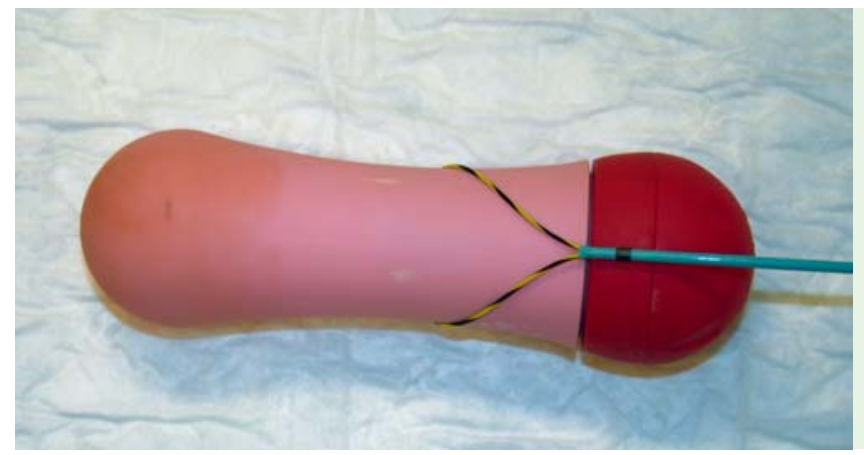

Fig. 3 Foreign body retrieved from the rectum.

Using a gastroduodenoscope, the giant snare was easily placed around the distal end of the vibrator. With gentle traction the vibrator was removed ( $\bullet$ Fig. 3 ).

Thus, when a standard polypectomy snare is too small to grasp a foreign body in the rectum, a giant snare can be made simply using a folded guide wire and an ERCP biliary stent pusher.

\section{Competing interests: None}

Endoscopy_UCTN_Code_TTT_1AO_2AL

\section{E. J. van der Wouden, B. D. Westerveld} Department of Gastroenterology and Hepatology, Isala Clinics, Zwolle, the Netherlands

\section{References}

1 Koornstra JJ, Weersma RK. Management of rectal foreign bodies: description of a new technique and clinical practice guidelines. World J Gastroenterol 2008; 14: 4403-4406

2 Lake JP, Essani R, Petrone P et al. Management of retained colorectal foreign bodies: predictors of operative intervention. Dis Colon Rectum 2004; 47: 1694-1698

\section{Bibliography}

DOI $10.1055 / \mathrm{s}-0029-1244009$

Endoscopy 2010; 42: E122

(c) Georg Thieme Verlag KG Stuttgart · New York . ISSN 0013-726X

\section{Corresponding author}

\section{E. J. van der Wouden}

Department of Gastroenterology and Hepatology Isala Clinics, location Sophia

PO Box 10400

8000 GK Zwolle

The Netherlands

Fax: +31-38-4243056

e.j.van.der.wouden@isala.nl 